\title{
Influence of Fruit-to-Fruit Contact on the Susceptibility of French Prune to Infection by Monilinia fructicola
}

\author{
Themis J. Michailides, Plant Pathologist, and David P. Morgan, Staff Research Associate, Department of Plant \\ Pathology, University of California, Davis, Kearney Agricultural Center, Parlier 93648
}

\begin{abstract}
Michailides, T. J., and Morgan, D. P. 1997. Influence of fruit-to-fruit contact on the susceptibility of French prune to infection by Monilinia fructicola. Plant Dis. 81:1416-1424.

In eight commercial prune (Prunus domestica cv. French) orchards, 43 to $69 \%$ of brown rot (caused by Monilinia fructicola or M. laxa) infections occurred in clustered fruit as opposed to solitary fruit. Fruit-to-fruit contact surfaces had cracked and thin cuticles and larger microcracks (up to 2,255 $\mu \mathrm{m}$ in length) surrounding the lenticels than those of non-contact surfaces (cracks up to $351 \mu \mathrm{m}$ in length). Furthermore, fruit-to-fruit contact surfaces retained greater proportions of methylene blue, indicating absence of epicuticular wax, than the non-contact surfaces. Carbohydrate content of exudates in water placed on fruit-to-fruit contact surfaces was 15 and $22 \mathrm{mg} / \mathrm{ml}$, while those of non-contact surfaces were 13 and $19 \mathrm{mg} / \mathrm{ml}$ after 15 and $28 \mathrm{~h}$, respectively. Conidia of $M$. fructicola germinated faster and at higher rates, and the incidence of infection was significantly higher on fruit-to-fruit contact than on non-contact surfaces. Densities of fungal CFU were greater $\left(27\right.$ to $\left.98 \mathrm{CFU} / \mathrm{cm}^{2}\right)$ on fruit-to-fruit contact compared to those of non-contact surfaces $\left(7\right.$ to $\left.29 \mathrm{CFU} / \mathrm{cm}^{2}\right)$. In four experiments, after spraying to runoff with distilled water, surfaces of solitary fruit dried after 7 to $8 \mathrm{~h}$ at $23 \pm 1{ }^{\circ} \mathrm{C}$ compared to 12 to $14 \mathrm{~h}$ for groups of 5 to 6 fruit. After spraying the same mature fruit with $1.2 \times 10^{5}$ conidia/ml of $M$. fructicola and incubating at $24^{\circ} \mathrm{C}$ and $>97 \%$ relative humidity, 26 to $70 \%$ and 38 to $100 \%$ of fruit placed in groups of 5 to 6 were infected after 3 days and 5 days, respectively, whereas only 2 to $13 \%$ and 21 to $65 \%$ of solitary fruit became infected. These results suggest that fruit-tofruit contact surfaces predispose prune fruit to infection by $M$. fructicola, and that it might be possible to reduce fruit losses from brown rot in prune orchards by thinning fruit to reduce fruit clustering, applying early summer fungicide sprays before fruit contact occurs, and ultimately, by selection for non-clustering cultivars in prune breeding programs.
\end{abstract}

Additional keywords: disease resistance, Monilinia laxa, predisposition

Brown rot of mature fruit of prune (Prunus domestica L. French) is the most destructive disease of prunes in California, causing severe fruit losses annually. Monilinia fructicola (G. Wint.) Honey is commonly isolated from infected prune fruit (23) but $M$. laxa (Aderhold \& Ruhland) Honey can also cause fruit decay. Both species can cause blossom blight under conditions favorable for infection (23).

Prune flowers are formed in buds that usually contain 2 flowers and no leaves (25), although at times as many as 4 flowers per bud may develop. The flower buds usually form laterally in the axils of the new growth of spurs. Spurs typically produce few nodes during a season's growth, so that internode elongation of the spur shoots is greatly suppressed relative to that

Corresponding author: Themis J. Michailides E-mail: themis@uckac.edu

This research was supported in part by the California Prune Board.

Accepted for publication 24 August 1997.

Publication no. D-1997-0922-01R

(C) 1997 The American Phytopathological Society with the other protective constituents on plant surfaces (13), provides the main constitutive defense barrier against pathogens of stone fruit such as $M$. fructicola $(1,4,15,19,20)$. The quantity and thickness of epicuticular wax and cuticle membrane on fruit can be influenced by environmental factors (14). In French prune, rains during and 1 week after full bloom prevented development of fruit cuticle (15). In addition, severe scabbing, termed wind scab, caused by developing fruit rubbing against other fruit, leaves, and shoots during strong north to northwest wind gusts, predisposed fruit to preharvest and postharvest fungal decay $(18,19)$.

The objectives of this study were to determine (i) the effect of fruit-to-fruit contact on cuticular characteristics, epicuticular wax formation, production of exudates, and presence of mycoflora; (ii) conditions created in fruit-to-fruit contact surfaces that affect the brown rot infection process; and (iii) the susceptibility of fruit-to-fruit contact surfaces to infection by $M$. fructicola. An abstract of this study has been published (20).

\section{MATERIALS AND METHODS}

Orchard surveys. A survey was conof the terminal shoots (25). As a result, fruit are produced in compact clusters ranging from 2 to more than 10, a growth pattern that results in numerous fruit-tofruit contacts among fruit as they enlarge during maturation. However, in the last several years, growers have adapted mechanical thinning in order to produce large size fruit and achieve high dry weight.

We observed that clustering of prunes was associated with the development of severe infections of mature fruit by Monilinia spp. In addition, we noted that infections in clustered fruit often began at the fruit-to-fruit contact surfaces and progressed to produce clusters of mummies covered with sporodochia of the pathogen.

Compactness in fruit inflorescences has been associated previously with susceptibility to disease. Grape cultivars with compact clusters were shown to be more susceptible to bunch rot caused by Botrytis cinerea $(12,29)$, and infections by $B$. cinerea were often initiated at berry-to-berry contact surfaces, which had shallow depressions, pores, and cracks $(12,24)$.

The plant cuticle consists of insoluble cutin polymers, which form the framework of the membrane, and soluble waxes deposited on the surface as epicuticular wax $(10,14)$. The cuticular membrane, along ducted in four prune orchards each in 1993 (coded as 931 to 934) and 1994 (coded as 941 to 944 ; Table 1). All the orchards were planted with the cultivar French prune. One to two days before the growers shook the trees to harvest the fruit, a total of 72 to 289 infected solitary and clustered fruit were recorded in 25 to 30 arbitrarily selected trees in these orchards. The distributions of $M$. fructicola between solitary and clustered infected fruit in each orchard in both 1993 and 1994 were analyzed using the Paired-Sample Sign Test for nonparametric tests analysis (11).

Fruit-to-fruit contact surface characteristics. Mature $(23.4 \%$ soluble solids; and $4.4 \mathrm{~kg} / \mathrm{cm}^{2}$ flesh firmness) French prune fruit from one orchard each in Fresno and Glenn counties, California, were used in the following experiments. After harvest, the fruit were stored at 0 to $1{ }^{\circ} \mathrm{C}$ until used. Clusters of healthy fruit were collected either by detaching connected peduncles bearing double, triple, or quadruple fruit or by cutting small twigs bearing 5 to 6 fruit.

Single and clustered fruit were stained with methylene blue to determine the density of epicuticular wax on different fruitto-fruit contact and non-contact surfaces. 
Fruit were submerged in a $0.25 \%$ solution of methylene blue in $95 \%$ ethanol for 1 to $2 \mathrm{~h}$ at $23^{\circ} \mathrm{C}$ and rinsed twice with deionized water. Tangential thin sections, including the skin of the fruit, were made by hand using a razor. The thin sections were mounted in water and examined for staining with a compound microscope.

To compare the topographical differences between fruit-to-fruit contact and non-contact fruit surfaces, imprints of respective areas were taken on microscope slides, using a household epoxy adhesive (GOOP, Eclectic Products, Inc., Carson, CA). A thin layer of the adhesive was spread on the respective surfaces, allowed to dry for 3 to $4 \mathrm{~h}$, peeled carefully, mounted in $0.5 \%$ Triton-X-100 surfactant solution, and examined with a compound microscope. Because a major difference between contact and non-contact fruit surfaces was the magnitude of splitting of the cuticular and epidermal layers along the lenticels, we measured the length of splitting in 3 slides ( 9 microscopic fields each for contact and non-contact surfaces) with 10 measurements per field. These results were compared using a pairwise Student's $t$ test. The experiment was repeated once with mature fruit collected from a commercial orchard.

Characteristics of cuticle in contact and non-contact surfaces of arbitrarily selected prunes, collected from two commercial orchards were determined with a compound and a scanning electron microscope, using methods adjusted for prune fruit $(15,19)$.

Effect of fruit-to-fruit contact on infection by $M$. fructicola. Mature paired prune fruit were collected from an experimental orchard at Kearney Agricultural Center. Fourteen fruit were placed singly on waxed wire screens in plastic containers so that the fruit-to-fruit contact surface was facing upwards. A tygon tubing $(6 \mathrm{~mm}$ in diameter by $6 \mathrm{~mm}$ high) was placed over the contact surface and $80 \mu \mathrm{l}$ of a suspension of $2.5 \times 10^{4}$ conidia of M. fructicola per milliliter (prepared from an infected prune fruit) was placed in the tygon tubing well. Similarly, fruit were inoculated on non-contact surfaces. To increase humidity, $200 \mathrm{ml}$ of water were poured into each container. The containers were covered and incubated at $24^{\circ} \mathrm{C}$, and the incidence of infected fruit and the diameter of decay lesions were recorded after 1,2, 3, 4, and 5 days incubation. There were three replications of 14 fruit each for each fruit type, and the experiment was repeated once. Treatment means were compared with a pair-wise Student's $t$ test.

Carbohydrate exudates. Mature prune fruit as described previously were collected from an experimental orchard at Kearney Agricultural Center on 2 and 9 September 1995. Twenty-four paired fruit, showing distinct fruit-to-fruit contact surfaces, were selected. The fruit were arranged in rows of 8 fruit with the contact surface facing up and 8 fruit with the contact surface facing down in a plastic container (24 by 31 by 11 $\mathrm{cm})$ over waxed wire screens. A small tygon tubing well $(6 \mathrm{~mm}$ in diameter, 6 $\mathrm{mm}$ high) was placed over the fruit-to-fruit contact surface or on the non-contact surface (for fruit with the contact surface facing down). An aliquot of $100 \mu \mathrm{l}$ of deionized water was poured in each well, removed from the well after 15 or $28 \mathrm{~h}$, and analyzed for carbohydrate content, using the cold anthrone test (27) at $625 \mathrm{~nm}$ absorbency with a Spec-21 spectrophotometer (Bausch \& Lomb Inc., Rochester, New York). The limit of detection for this analysis was $0.15 \mathrm{mg} / \mathrm{ml}$. Three replications of 8 fruit each were used, and the experiment was repeated once. The carbohydrate contents $(\mathrm{mg} / \mathrm{ml}$ aliquot) exuded into the deionized water from fruit-to-fruit contact and non-contact surfaces were compared with a pair-wise Student's $t$ test.

Effects of altering characteristics of fruit surface on infection. The following five treatments were used. Using mature French prunes as described above, an area of 1 to $2 \mathrm{~cm}^{2}$ of the side surface of 21 fruit each were wiped with cotton dipped in (i) chloroform, (ii) ethanol, or (iii) not dipped in any solution (used dry); (iv) similarly, 1 to $2 \mathrm{~cm}^{2}$ of the side surface were scraped with a razor blade, without cutting the fruit skin, to remove both epicuticular wax and

Table 1. Distribution ${ }^{\mathrm{x}}$ of infections by Monilinia fructicola between solitary and clustered fruit in commercial French prune orchards in 1993 and 1994

\begin{tabular}{lccc}
\hline Orchard & Year & Clustered fruit $(\boldsymbol{\%})^{\mathbf{y}, \mathbf{z}}$ & Solitary fruit (\%) \\
\hline 931 & 1993 & 66.2 & 33.8 \\
932 & 1993 & 43.2 & 56.8 \\
933 & 1993 & 58.3 & 41.7 \\
934 & 1993 & 63.6 & 38.4 \\
941 & 1994 & 69.4 & 30.6 \\
942 & 1994 & 61.5 & 38.5 \\
943 & 1994 & 68.0 & 32.0 \\
944 & 1994 & 54.0 & 46.0 \\
\hline
\end{tabular}

${ }^{\mathrm{x}}$ Distribution is based on 72 to 289 infections recorded in 25 to 30 trees selected arbitrarily in each orchard; orchards were located in Butte, Glenn, and Tehama counties.

${ }^{y}$ Clustered infections involved at least 2 and up to 12 fruit per cluster.

${ }^{z}$ Using the paired-sample sign test for nonparametric tests analysis (11), the frequency of clusters of infected fruit was significantly greater $(\alpha=0.020)$ than that of single infected fruit.

the superficial layers of the cuticle; and (v) fruit not treated with any of the above methods served as controls. Fruit from each treatment were arranged flat in rows of 7 in a plastic container over waxed wire screens. A small piece tygon tubing well (6 $\mathrm{mm}$ in diameter, $6 \mathrm{~mm}$ high) was placed on the treated and nontreated areas, and $80 \mu \mathrm{l}$ of a suspension of $2 \times 10^{4}$ conidia/ml of $M$.

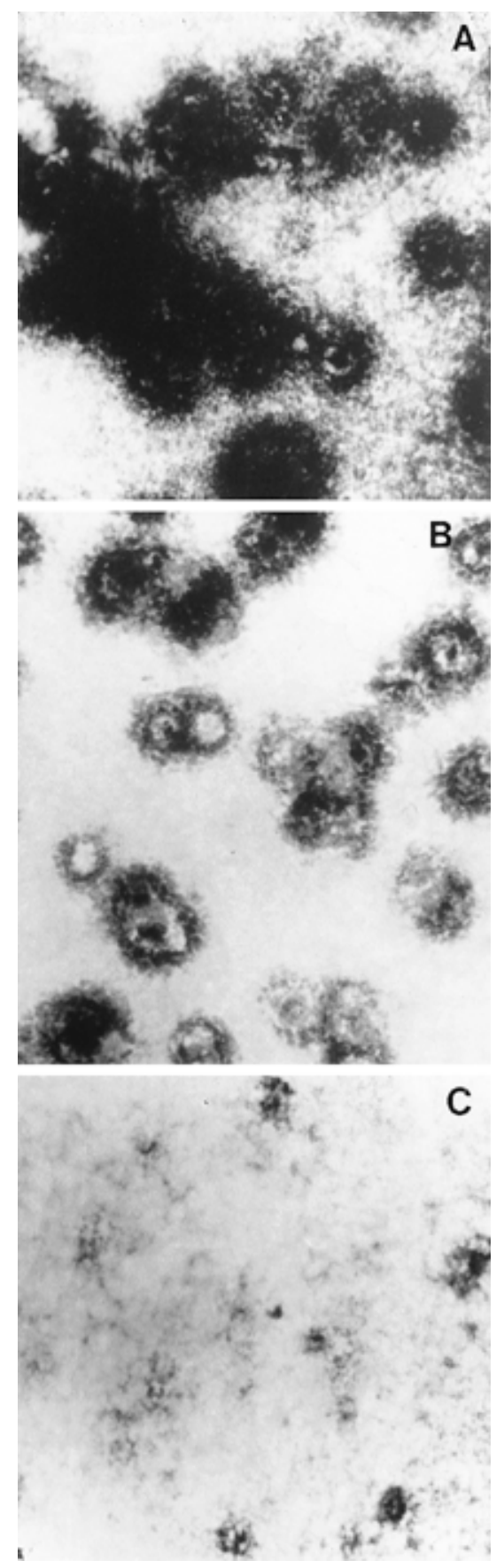

Fig. 1. Tangential sections of mature prune fruit skins stained with methylene blue. (A) Heavily stained section (long dark areas represent micro-cracks); (B) less darkly stained section representing extensive areas around lenticels lacking epicuticular wax on fruit contact surfaces; and (C) section from non-contact surface showing no penetration of stain because of the thick epicuticular wax and the lack of microcracks. (A, B, C, 25×) 
fructicola were placed in the tubing well. The purpose of the tygon tubing well was to hold the inoculum on the treated surface so that it wouldn't roll off the hydrophobic fruit surface. There were three replications of 7 fruit each, and the experiment was repeated twice (once each in 1995 and 1996). The incidence of infection was measured after 1, 2, 3, 4, and 5 days' incubation at $23^{\circ} \mathrm{C}$. For each incubation time, treatment means were compared with Fisher's protected least significance test $(P$ $=0.05$ ).

Conidial germination on fruit-to-fruit contact and non-contact surfaces. Conidial masses of $M$. fructicola were carefully removed from the surface of an infected fruit using a transfer loop without touching the surface of the fruit. Conidia were washed off the transfer loop by placing the loop in a test tube containing sterile distilled water. Four (in Exp. 1) and eight (in Exp. 2) prune fruit, each with fruit-tofruit contact surfaces, and respective fruit without contact surfaces, were used for these experiments. Contact surfaces were marked by making a ring about 5 to $10 \mathrm{~mm}$ in diameter with melted cooking wax. The test tube containing the spore suspension was shaken vigorously for $2 \mathrm{~min}$ and strained through 4 layers of sterile cheesecloth to eliminate unbroken chains of conidia, conidiophore parts, and mycelia. A $100-\mu l$ drop of spore suspension $\left(1.2 \times 10^{5}\right.$ spores $/ \mathrm{ml}$ ) was placed in the center of each pre-marked area on the surface of each fruit, and all fruit were incubated in a plastic container with clean, wet paper towels in the bottom. After incubation for 3 or 5 $\mathrm{h}$, the spore suspension drop on the surface was agitated and $20 \mu \mathrm{l}$ of the spore suspension were removed, placed on a grooved sterile microscope slide, and covered with a cover slip. Germination of conidia was determined immediately, using a compound microscope $(100 \times)$. Three replicates

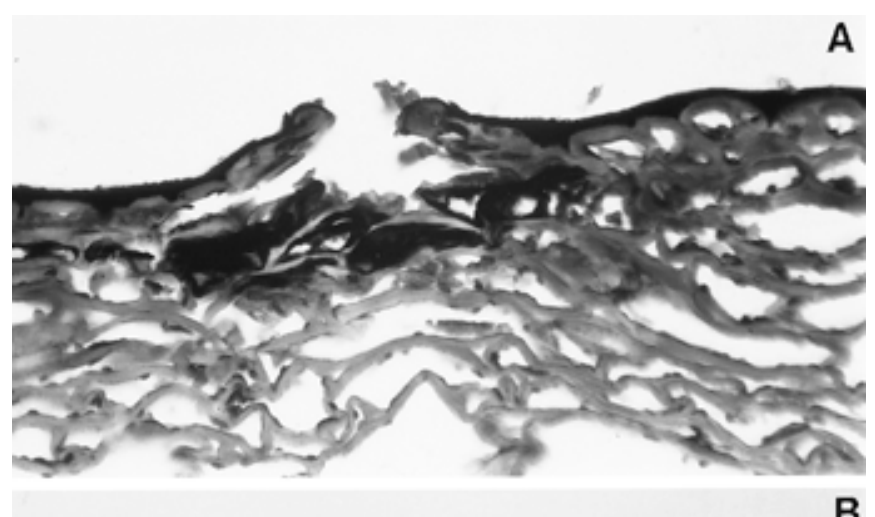

B

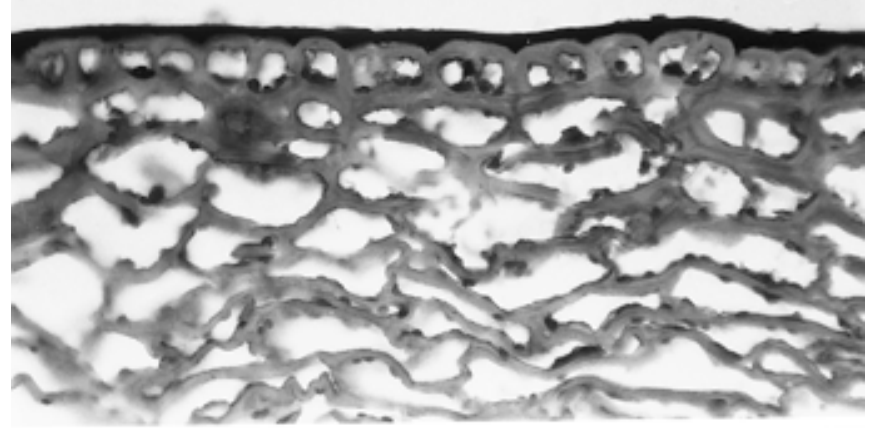

C

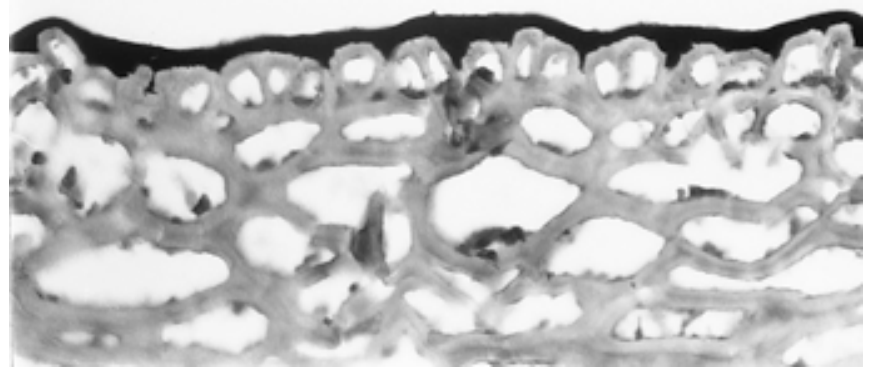

Fig. 3. Cross-sections of mature French prune fruit stained with Sudan IV in ethanol. Section of contact surface (A) with a micro-crack and (B) without micro-cracks and flattened epidermal and subepidermal cells. (C) Non-contact surface showing well-developed, intact cuticle and non-flattened epidermal and subepidermal cells. (A, B, C, 250×)

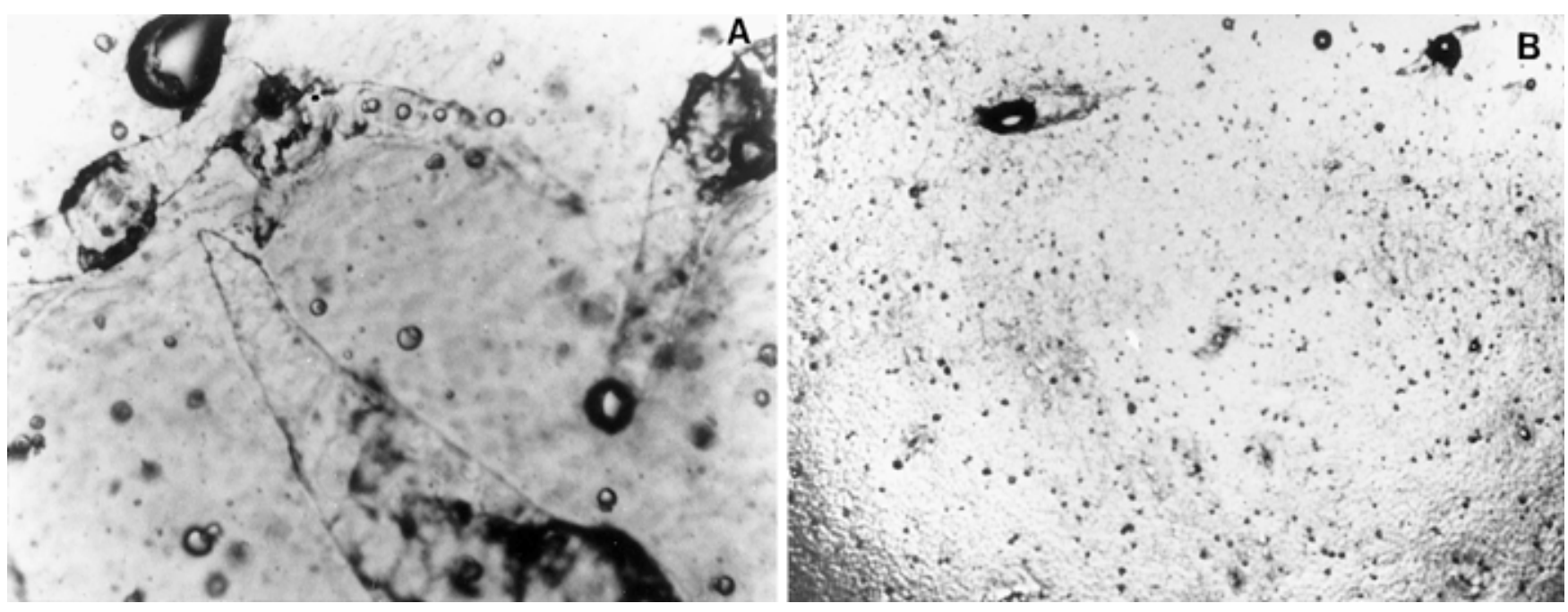

Fig. 2. Epoxy glue imprints of mature prune epidermal tissues showing (A) micro-cracks in contact and (B) lack of micro-cracks in non-contact surfaces. (A, 100×; B, 25×) 
of 100 conidia each were counted per fruit each time. The experiment was conducted two times. For comparison, conidial germination was also determined in petri dishes containing acidified $(2.5 \mathrm{ml}$ of a $25 \%$ [ $\mathrm{vol} / \mathrm{vol}]$ lactic acid per liter medium) potato dextrose agar (APDA), or on grooved slides with $50 \mu \mathrm{l}$ water or water mixed with prune juice (resulting in $1.15 \%$ soluble sugars) and $1.2 \times 10^{4}$ spores $/ \mathrm{ml}$. Germination was determined by counting three replicates of 100 conidia. Data were analyzed with analysis of variance using Fisher's protected least significant difference $(P=0.05)$ for mean separation and for an indication of the confidence interval for differences. All analyses were done with SAS (release 6.04, SAS Institute Inc., Cary, NC).

Mycoflora associated with fruit-tofruit contact surfaces. The mycoflora associated with fruit-to-fruit contact and non-contact surfaces were determined in samples of mature fruit collected from two commercial orchards in late August. A cork borer, $1 \mathrm{~cm}$ in diameter, was used to remove disks, including the outer skin of the surface of fruit. The fruit flesh was carefully removed with a sterile razor, leaving only the fruit skin and 2 to $3 \mathrm{~mm}$ of flesh. These sections were then placed without surface sterilization in a sterile test tube containing $9 \mathrm{ml}$ of sterile water. Four disks of contact surfaces obtained from 2 paired fruit in contact were used per test tube. In addition, 4 disks $(1 \mathrm{~cm}$ in diameter) from non-contact surface areas from the same fruit were placed per test tube and used as controls. Five test tubes (replicates) were used. Each test tube was shaken for $1 \mathrm{~min}$, and aliquots of $150 \mu \mathrm{l}$ were plated on each of 4 dishes containing APDA and incubated at $23 \pm 1{ }^{\circ} \mathrm{C}$. Colonies of filamentous fungi and yeasts were identified and counted after 5 days' incubation.

To determine the levels of colonization of fruit surfaces by various fungi, the water washings were discarded and the same disks were surface sterilized with a $0.1 \%$ chlorine (prepared from a $5.25 \%$ sodium hypochlorite solution) for $10 \mathrm{~min}$, rinsed three times with sterile distilled water, and plated on APDA dishes. The dishes were incubated at $23^{\circ} \mathrm{C}$ and fungi that developed from the plant tissues were identified and recorded after 5 to 10 days' incubation. Five dishes, each containing 4 disks of fruit-to-fruit contact and non-contact surfaces of fruit samples, were used. The experiment was repeated twice with fruit collected from a different orchard. To determine that free fungal or yeast propagules did not survive in the chlorine washing liquid, triplicate $50-\mu \mathrm{l}$ aliquots from each test tube were plated in the center of a small petri dish containing APDA. The dishes were examined for mycelial growth after 5 days' incubation at $23 \pm$ $1{ }^{\circ} \mathrm{C}$.

Effect of artificial fruit-to-fruit contact on water retention and infection by

Table 2. Effect of fruit-to-fruit contact created in the orchard on the susceptibility of mature French prune fruit to Monilinia fructicola in the laboratory

\begin{tabular}{lcccccr}
\hline & & \multicolumn{5}{c}{ Percent fruit infected after day $^{\mathbf{x}}$} \\
\cline { 3 - 7 } Experiment & Treatment $^{\mathbf{y}}$ & $\mathbf{1}$ & $\mathbf{2}$ & $\mathbf{3}$ & $\mathbf{4}$ & $\mathbf{5}$ \\
\hline 1 & Contact & 0 & $86^{* \mathrm{z}}$ & $96^{*}$ & $100^{*}$ & 100 \\
& Control & 0 & 23 & 41 & 79 & 98 \\
2 & Contact & 0 & $55^{*}$ & $75^{*}$ & 97 & 100 \\
& Control & 0 & 25 & 39 & 89 & 100 \\
\hline
\end{tabular}

${ }^{\mathrm{x}}$ Based on three replications of 14 fruit in each type of fruit.

y Fruit were inoculated with $80 \mu \mathrm{l}$ of a suspension of $2.5 \times 10^{4}$ conidia of $M$. fructicola per milliliter, and incubated at $23^{\circ} \mathrm{C}$

$\mathrm{z} *$ indicates significant difference between fruit-to-fruit contact and non-contact surfaces for each incubation time using a Student $t$ test at $P=0.05$.

Table 3. Effect of fruit-to-fruit contact on the susceptibility of mature French prune fruit to Monilinia fructicola, determined by comparing lesion diameters on inoculated fruit

\begin{tabular}{lcccccc}
\hline & & \multicolumn{5}{c}{ Diameter of lesion $(\mathbf{m m})$ after day $^{\mathbf{x}}$} \\
\cline { 3 - 7 } Experiment & Treatment $^{\mathbf{y}}$ & $\mathbf{1}$ & $\mathbf{2}$ & $\mathbf{3}$ & $\mathbf{4}$ & $\mathbf{5}$ \\
\hline 1 & Contact & 0 & 14 & $23^{* \mathrm{z}}$ & $29^{*}$ & $32^{*}$ \\
& Control & 0 & 12 & 19 & 24 & 28 \\
2 & Contact & 0 & 12 & 21 & 25 & 30 \\
& Control & 0 & 11 & 19 & 23 & 29 \\
\hline
\end{tabular}

${ }^{\mathrm{x}}$ Averages of three replications, with only infected fruit included in each replication.

y Fruit were inoculated with $80 \mu \mathrm{l}$ of a suspension of $2.5 \times 10^{4}$ conidia of $M$. fructicola per milliliter, and incubated at $23^{\circ} \mathrm{C}$

$\mathrm{z} *$ indicates significant difference between fruit-to-fruit contact and non-contact surfaces for each incubation time using a Student $t$ test at $P=0.05$.
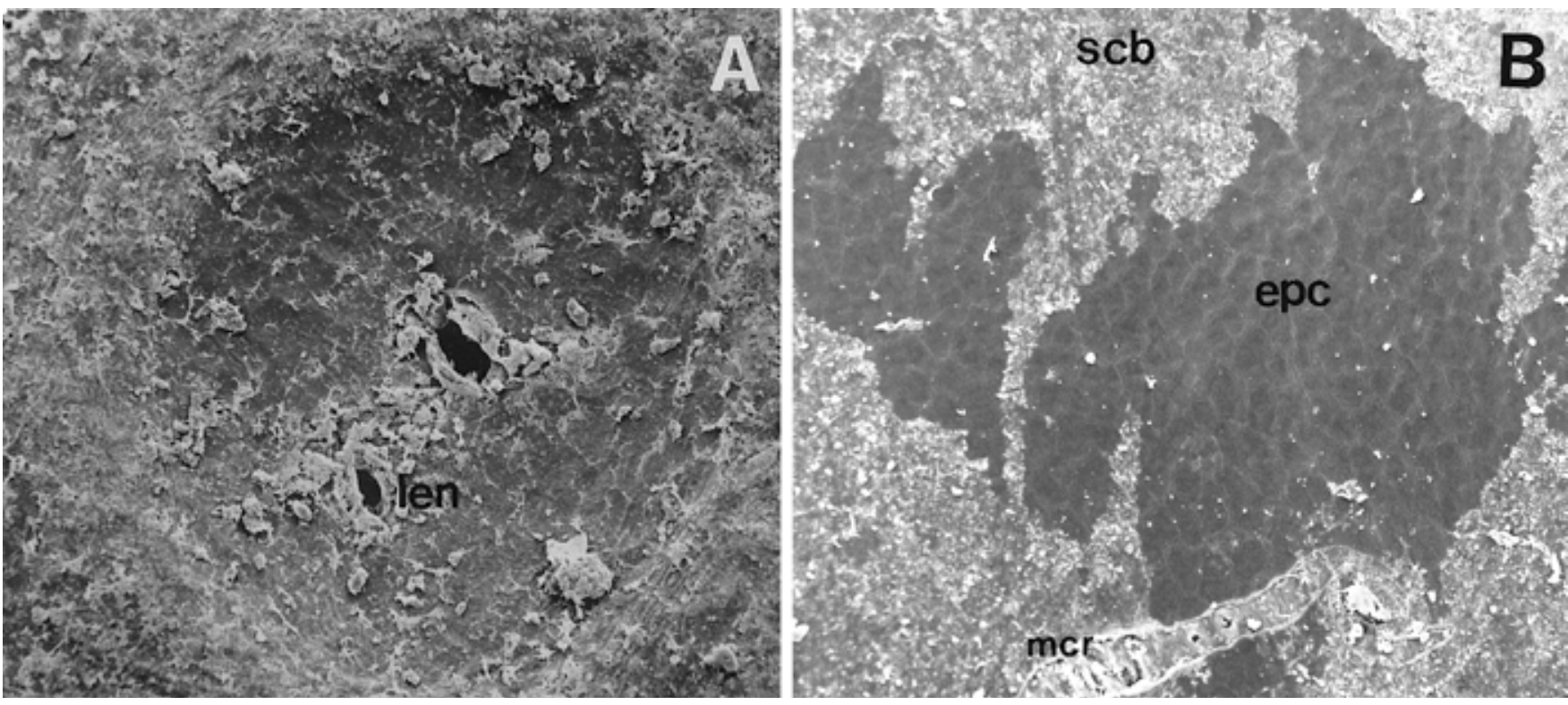

Fig. 4. Scanning electron micrographs of $(\mathbf{A})$ non-contact $($ len $=$ lenticel) and $(\mathbf{B})$ contact surfaces of French prune. Note in $(\mathbf{B})$ extensive areas lacking epicuticular wax revealing the outlines of epidermal cells (epc) and presence of scabby (scb) areas with micro-cracks (mcr). (A, 185×; B, 110×) 
M. fructicola. Mature prune fruit were harvested with their stems attached in late August in 1992 and 1993 from a commercial orchard, and surface disinfected for 3 min in a solution containing $0.1 \%$ chlorine solution prepared as above. After drying, 36 prunes were placed in plastic containers ( 24 by 31 by $11 \mathrm{~cm}$ ) over waxed wire screens $(1 \mathrm{~cm}$ opening) either solitarily (six rows of 6 fruit each) or in seven groups of 5 or 6 , arranging 4 fruit in contact on the bottom and 1 or 2 on top (to create an artificial cluster of fruit). Stem scars in fruit with broken stems were covered with melted wax. Solitary and grouped fruit were sprayed to runoff with sterile, deionized water and the containers were then left uncovered on a laboratory bench $\left(23^{\circ} \mathrm{C}\right.$ and 55 to $60 \%$ relative humidity). Fruit were examined hourly for 12 to $14 \mathrm{~h}$ for the presence of drops of water on their surface.

After all fruit surfaces were free of water, the same fruit used in the water retention experiments were sprayed to runoff with a de Vilbiss atomizer, using a suspension of $1.2 \times 10^{5}$ conidia/ml of $M$. fructicola grown on PDA. The plastic containers were left uncovered for $24 \mathrm{~h}$, then covered after adding $250 \mathrm{ml}$ of deionized water to the container. Disease on fruit in containers was recorded after 3, 4, and 5 days (1992) and 3, 5, and 7 days (1993). Three plastic containers (replicates) of 36 fruit each were used in two experiments each in 1992 and 1993. Comparisons of incidence of infection were made with a pairwise Student $t$ test.

\section{RESULTS}

Orchard surveys. In each year, the distribution of brown rot in clustered fruit was significantly ( $\alpha=0.020$ ) greater than that in solitary infected fruit in all orchards except for orchard 932 (Table 1).

Effect of fruit-to-fruit contact surface characteristics. Prunes stained with methylene blue for 1 to $2 \mathrm{~h}$ showed dark staining on the fruit-to-fruit contact surfaces (marked prior to treatment; Fig. 1A) and very light staining (mainly along some of the lenticels) in non-contact surfaces (Fig. 1C). Superficial sections viewed with a compound microscope indicated that the dark blue staining in contact surfaces was associated only with lenticels and microcracks (Fig. 1A), or with lenticels alone when micro-cracks were missing (Fig. 1B), while the majority of lenticels in non-contact surfaces were not stained (Fig. 1C). Areas between the lenticels in contact surfaces stained dark blue, representing cracks originating from the lenticels lacking epicuticular wax.

Cracking was made obvious by using the epoxy-glue technique. The length of cracking in fruit-to-fruit contact surfaces ranged from 730 to $2,255 \mu \mathrm{m}$ (Fig. 2A), while cracking on non-contact surfaces ranged from 212 to $350 \mu \mathrm{m}$ (Fig. 2B). The average length of cracking in fruit-to-fruit contact surfaces was significantly $(P<$ $0.01)$ greater than for the non-contact surfaces. Branching of cracks and the presence of mycelium from developing fungi were found only in cracks of the fruit-tofruit contact surfaces.

Staining thin cross-sections of the surface tissues with Sudan IV to observe the cuticles revealed thinner cuticles in fruitto-fruit contact than in non-contact surfaces, with numerous interruptions that were associated with cracks and lenticels (Fig. 3A). In addition, the epidermal layer and a few cell layers beneath the epidermis were compressed in sections of contact surfaces (Fig. 3A-B). In contrast, noncontact surfaces had thick, well-developed cuticles, were usually uninterrupted, and the epidermal and underlying cell layers were not compressed (Fig. 3C).

Scanning electron microscopy showed differences in the surface of non-contact and contact areas. Non-contact areas were covered with dense grains, flakes, and strands of epicuticular waxes, which make up the wax bloom of mature prune fruit (Fig. 4A). Contact surfaces showed areas lacking wax flakes and grains, and the outlines of the epidermal cells were visible (epc in Fig. 4B). Other areas showed micro-cracks (mcr in Fig. 4B) and areas where the integrity of the fruit surface was destroyed, appearing scabby (scb in Fig. 4B).

Effect of fruit-to-fruit contact on infection by $\boldsymbol{M}$. fructicola. Between 55 and $86 \%$ of the fruit were infected 2 days after inoculation on the fruit-to-fruit contact surfaces, in comparison with only 23 to

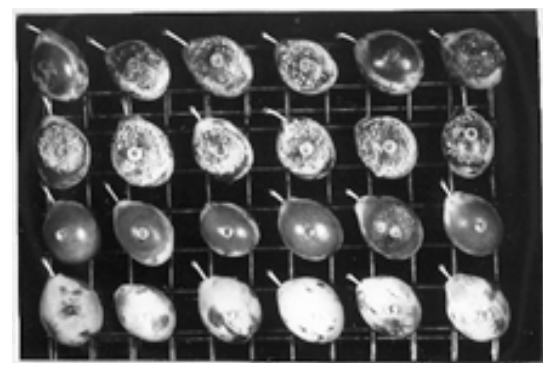

Fig. 5. Development of brown rot infections on inoculated prune fruit after 4 days' incubation at $23^{\circ} \mathrm{C}$ as affected by wiping the fruit surface with ethyl alcohol (top row), chloroform (second row), or a dry cotton swap (third row). Untreated fruit (bottom row) appear white because of the dense epicuticular wax.

Table 4. Effects of various treatments of the surface of mature French prune fruit on the susceptibility to brown rot caused by Monilinia fructicola

\begin{tabular}{|c|c|c|c|c|c|c|}
\hline \multirow[b]{2}{*}{ Experiment } & \multirow[b]{2}{*}{ Treatment } & \multicolumn{5}{|c|}{ Percentage of infected fruit after day } \\
\hline & & 1 & 2 & 3 & 4 & 5 \\
\hline \multicolumn{7}{|c|}{1 (prune 1995) } \\
\hline & Scraped $^{\mathrm{w}}$ & $100.0 \mathrm{a}^{\mathrm{x}}$ & $100.0 \mathrm{a}$ & $100.0 \mathrm{a}$ & $100.0 \mathrm{a}$ & $100.0 \mathrm{a}$ \\
\hline & Chloroform $^{\mathrm{y}}$ & $0.0 \mathrm{~b}$ & $81.0 \mathrm{ab}$ & $100.0 \mathrm{a}$ & $100.0 \mathrm{a}$ & $100.0 \mathrm{a}$ \\
\hline & Ethanol $^{\mathrm{y}}$ & $0.0 \mathrm{~b}$ & $51.6 \mathrm{ab}$ & $85.7 \mathrm{a}$ & $95.2 \mathrm{a}$ & $95.2 \mathrm{a}$ \\
\hline & Wiped ${ }^{\mathrm{y}}$ & $0.0 \mathrm{~b}$ & $46.7 \mathrm{ab}$ & $95.2 \mathrm{a}$ & $95.2 \mathrm{a}$ & $100.0 \mathrm{a}$ \\
\hline & Control & $0.0 \mathrm{~b}$ & $0.0 \mathrm{~b}$ & $55.6 \mathrm{~b}$ & $60.3 \mathrm{~b}$ & $95.2 \mathrm{a}$ \\
\hline \multicolumn{7}{|c|}{2 (prune 1995) } \\
\hline & Scraped & $56.6 \mathrm{a}$ & $100.0 \mathrm{a}$ & $100.0 \mathrm{a}$ & $100.0 \mathrm{a}$ & $100.0 \mathrm{a}$ \\
\hline & Chloroform & $0.0 \mathrm{~b}$ & $84.1 \mathrm{a}$ & $100.0 \mathrm{a}$ & $100.0 \mathrm{a}$ & $100.0 \mathrm{a}$ \\
\hline & Ethanol & $0.0 \mathrm{~b}$ & $75.4 \mathrm{a}$ & $100.0 \mathrm{a}$ & $100.0 \mathrm{a}$ & $100.0 \mathrm{a}$ \\
\hline & Wiped & $0.0 \mathrm{~b}$ & $35.7 b$ & $79.4 \mathrm{ab}$ & $100.0 \mathrm{a}$ & $100.0 \mathrm{a}$ \\
\hline & Control & $0.0 \mathrm{~b}$ & $4.8 \mathrm{c}$ & $56.3 \mathrm{~b}$ & $76.2 \mathrm{~b}$ & $90.5 \mathrm{a}$ \\
\hline \multicolumn{7}{|c|}{3 (prune 1996) } \\
\hline & Scraped & $\ldots^{\mathrm{z}}$ & $95.8 \mathrm{a}$ & $100.0 \mathrm{a}$ & $100.0 \mathrm{a}$ & $100.0 \mathrm{a}$ \\
\hline & Chloroform & $\ldots$ & $83.3 \mathrm{a}$ & $100.0 \mathrm{a}$ & $100.0 \mathrm{a}$ & $100.0 \mathrm{a}$ \\
\hline & Ethanol & $\ldots$ & $58.5 \mathrm{~b}$ & $91.7 \mathrm{a}$ & $100.0 \mathrm{a}$ & $100.0 \mathrm{a}$ \\
\hline & Wiped & $\ldots$ & $21.0 \mathrm{c}$ & $50.0 \mathrm{~b}$ & $62.5 \mathrm{~b}$ & $62.5 \mathrm{~b}$ \\
\hline & Control & $\ldots$ & $0.0 \mathrm{~d}$ & $33.3 \mathrm{~b}$ & $50.0 \mathrm{~b}$ & $54.2 \mathrm{~b}$ \\
\hline
\end{tabular}

\footnotetext{
${ }^{\mathrm{v}}$ Each fruit was inoculated with $80 \mu \mathrm{l}$ of a suspension of $2 \times 10^{4}$ conidia/ml of $M$. fructicola placed on the treated fruit surface area.

${ }^{w}$ These fruit were scraped with a razor to remove epicuticular wax and superficial waxy layers of the fruit cuticle.

${ }^{x}$ For each incubation time, means were compared with Fisher's protected least significance test at $P=0.05$.

y An area of 1 to $2 \mathrm{~cm}^{2}$ on the side surface was wiped with dry cotton, or cotton dipped in chloroform, or ethanol.

${ }^{\mathrm{z}}$ Not recorded.
} 
$25 \%$ in fruit inoculated at the non-contact surfaces (Table 2). These differences in incidence of infection remained significant until day 4 (experiment 1) and day 3 (experiment 2) of incubation, but after day 5 the differences between fruit-to-fruit contact and non-contact inoculations were not significant (Table 2). In general, lesion diameters were significantly smaller for the infection at non-contact than fruit-tofruit contact in experiment 1 but not in experiment 2 (Table 3 ).

Carbohydrate exudates. Significantly $(P<0.05)$ more carbohydrate contents were measured in exudates from fruit-tofruit contact $(14.9 \mathrm{mg} / \mathrm{ml})$ than from noncontact surface $(13.5 \mathrm{mg} / \mathrm{ml}) 15 \mathrm{~h}$ after applying the water drops on the fruit surface. After $28 \mathrm{~h}$, the content of carbohydrate increased in general, but there was still a significant difference $(22.2 \mathrm{mg} / \mathrm{ml}$ for fruit-to-fruit contact surfaces versus $19.2 \mathrm{mg} / \mathrm{ml}$ for non-contact surfaces). Similar levels of carbohydrates were measured in the second experiment.

Effects of altering characteristics of fruit surface on infection. Scraping the cuticle with a razor without cutting the fruit cuticle resulted in 56.6 to $100 \%$ of infection within 1 day after fruit inoculation (Table 4). Significant levels of fruit in all treatments in which the fruit wax was removed showed signs of infection 2 days after inoculation, while a maximum of $5 \%$ of the fruit with intact surface were infected. In experiments 1 and 2, only fruit with intact surfaces had lower levels of infection 4 days after inoculation, while most or all of the fruit whose cuticle was treated were infected (Table 4 and Fig. 5). In experiment 3 , fruit wiped with dry cotton and control fruit still showed significantly $(P<0.05)$ lower levels of infection than fruit treated otherwise 4 and 5 days after inoculation, respectively. In general, wiping the epicuticular wax with dry cotton resulted in lower infection incidence than scraping or wiping the fruit surface with chloroform or ethyl alcohol 2 to 4 days after inoculation (Fig. 5).

Conidial germination on fruit-to-fruit contact and non-contact surfaces. Because the results were similar in the two experiments, only those of experiment 1 are presented in Table 5. Conidia of $M$. fructicola germinated faster on APDA, in a

Table 5. Germination and germ tube elongation of conidia of Monilinia fructicola placed on fruit-tofruit contact and non-contact surfaces of mature French prunes incubated at $23^{\circ} \mathrm{C}$

\begin{tabular}{|c|c|c|c|}
\hline \multirow[b]{2}{*}{ Treatment $^{\mathrm{u}}$} & \multicolumn{2}{|c|}{ Conidial germination $(\%)$ after $^{t}$} & \multirow[b]{2}{*}{ Germ tube length $(\mu \mathrm{m})$ after $5 \mathrm{~h}^{\prime}$} \\
\hline & $3 \mathbf{h}$ & $5 \mathbf{h}$ & \\
\hline Acidified PDA ${ }^{w}$ & 99.0 & 99.0 & $\ldots^{\mathrm{x}}$ \\
\hline Prune juice ${ }^{y}$ & 96.5 & 98.5 & $\ldots$ \\
\hline Sterile water & 94.5 & 99.0 & \\
\hline Contact surface & 87.5 & 92.0 & $78.7 \pm 22.2$ \\
\hline Non-contact surface & 75.5 & 76.5 & $59.5 \pm 25.3$ \\
\hline $\operatorname{LSD}^{\mathrm{z}}(P<0.05)$ & 6.0 & 3.2 & \\
\hline
\end{tabular}

${ }^{t}$ Average of four replications with three counts of 100 conidia per replication.

u One hundred $\mu \mathrm{l}$ of a $10^{5}$-conidia/ml suspension were used in each treatment.

${ }^{v}$ Averages of 20 random germinated spores.

${ }^{\mathrm{w}}$ Potato dextrose agar.

${ }^{\mathrm{x}}$ Impossible to measure because of intermingling germ tubes and mycelial branches.

${ }^{y}$ Prune juice was obtained from 2 ripe fruit and had $11.5 \%$ soluble sugars after dilution, used for the conidia germination experiments.

${ }^{\mathrm{z}}$ Least significant difference.

solution prepared from diluted prune juice (resulting in $1.15 \%$ carbohydrates), or in sterile water than on the fruit surface after 3 or $5 \mathrm{~h}$ incubation (Table 5). Significantly more conidia of $M$. fructicola germinated on fruit-to-fruit contact surfaces than on non-contact surfaces after $5 \mathrm{~h}$ incubation of conidia on the fruit surface. Germ tubes from conidia placed on fruit-to-fruit contact surfaces averaged $83 \mu \mathrm{m}$, compared to $60 \mu \mathrm{m}$ for those on non-contact surfaces after $5 \mathrm{~h}$ incubation at $23^{\circ} \mathrm{C}$. Measuring germ tubes in the rest of the treatments was impossible due to excessive growth and intermingling of the germ tubes.

Mycoflora associated with fruit-tofruit contact surfaces. In all experiments, the levels of mycoflora recovered from washings of fruit-to-fruit contact surfaces of fruit were more than three times greater than those recovered from non-contact surfaces (Table 6). In general, more colonies of $M$. fructicola developed from washings from fruit-to-fruit contact than non-contact surfaces. After surface sterilization, more $(P<0.05) M$. fructicola developed from disks of fruit-to-fruit contact surfaces when plated on APDA than those from non-contact surfaces (Table 6). Washings of sterilized fruit skin disks did not produce any fungal colonies on APDA dishes incubated at $23 \pm 1^{\circ} \mathrm{C}$ for 5 days.

More than $90 \%$ of the mycoflora on both kinds of surfaces were Aureobasidium pullulans (de Bary) G. Arnaud. Other fungi recovered sporadically were Alternaria alternata (Fr.) Keissl., and species of $A l$ ternaria, Cladosporium, Fusarium, Phomopsis, and Penicillium, Botrytis cinerea Pers.:Fr., Aspergillus niger v. Tiegh., and Epicoccum purpurascens Ehrenb. Among the yeasts recovered, Rodotorula spp. were relatively frequent. Densities of CFU of $M$. fructicola and other filamentous fungi were greater $\left(27\right.$ to $98 \mathrm{CFU} / \mathrm{cm}^{2}$ ) on fruit-to-fruit contact compared to those of non-contact surfaces ( 7 to $29 \mathrm{CFU} / \mathrm{cm}^{2}$ ). A. pullulans

Table 6. Monilinia fructicola and other mycoflora associated with fruit-to-fruit contact and non-contact surfaces of mature French prunes

\begin{tabular}{|c|c|c|c|c|}
\hline Experiment & Site of fruit surface removal ${ }^{v}$ & Fungal CFU/ cm$^{2}$ fruit surface ${ }^{w}$ & $\begin{array}{l}\text { Total no. of } M . \text { fructicola } \\
\text { colonies in } 20 \text { dishes }\end{array}$ & $\begin{array}{l}\text { No. of fruit skin disks } \\
\text { with } M \text {. fructicola } / 20^{\mathrm{x}}\end{array}$ \\
\hline \multicolumn{5}{|l|}{1} \\
\hline & Contact & 26.9 & 3 & 2 \\
\hline & Non-contact & 7.3 & 0 & 1 \\
\hline & $\operatorname{LSD}^{\mathrm{y}}(P<0.05)$ & 5.5 & $\ldots^{\mathrm{z}}$ & $\ldots$ \\
\hline \multicolumn{5}{|c|}{ 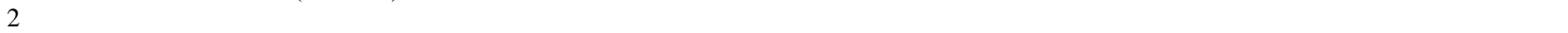 } \\
\hline & Contact & 98.0 & 5 & 6 \\
\hline & Non-contact & 29.7 & 1 & 2 \\
\hline & $\operatorname{LSD}(P<0.05)$ & 23.6 & $\ldots$ & $\ldots$ \\
\hline \multicolumn{5}{|c|}{ 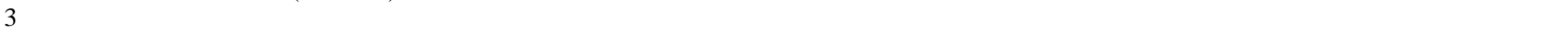 } \\
\hline & Contact & 54.3 & 5 & 1 \\
\hline & Non-contact & 17.1 & 0 & 0 \\
\hline & $\operatorname{LSD}(P<0.05)$ & 17.0 & $\ldots$ & $\ldots$ \\
\hline
\end{tabular}

${ }^{\mathrm{v}}$ Four disks, each $1 \mathrm{~cm}$ in diameter, were obtained from 2 paired fruit and placed in $9 \mathrm{ml}$ of sterile water.

w After shaking for $1 \mathrm{~min}, 150 \mu \mathrm{l}$ of the washings were plated on 4 acidified potato dextrose agar dishes for each of the five replications; colonies of filamentous fungi and yeasts were counted after 4 days.

x After discarding the washings, the fruit skin disks were surface-disinfected in $0.1 \%$ chlorine for $10 \mathrm{~min}$, rinsed with sterile water, and plated on dishes with acidified potato dextrose agar; $M$. fructicola was recorded after 5 days.

${ }^{\mathrm{y}}$ Least significant difference.

${ }^{\mathrm{z}}$ Not applicable. 
was removed in greater numbers from fruit-to-fruit contact surfaces (51 to 186 $\left.\mathrm{CFU} / \mathrm{cm}^{2}\right)$ than from non-contact surfaces (12 to $59 \mathrm{CFU} / \mathrm{cm}^{2}$; all data not shown). No antagonistic effects were noticed on $M$. fructicola colonies growing in the proximity of A. pullulans (T. J. Michailides, unpublished).

Effect of artificial fruit-to-fruit contact on water retention and infection by M. fructicola. In all experiments, water was retained much longer on fruit-to-fruit contact than on non-contact surfaces (Fig. 6). Although $100 \%$ of both fruit placed solitarily and in groups of 5 to 6 fruit were wet $2 \mathrm{~h}$ after spraying, after 3 and $4 \mathrm{~h}$ only 15 and $12 \%$ of the solitary fruit were still wet, respectively, compared with about 97 and $87 \%$ of the fruit arranged in groups. None of the solitary fruit were wet after 8 $\mathrm{h}$, but $48 \%$ of the fruit arranged in groups of 5 to 6 fruit were wet (Fig. 6). For all experiments, fruit-to-fruit contact surfaces of the fruit arranged in groups were free of any water drops after 12 to $14 \mathrm{~h}$ incubation.

In all experiments, 6 to 13 times more prunes arranged in groups of 5 to 6 fruit were infected after 3 days' incubation than fruit incubated solitarily, and the difference remained significant for 5 to 7 days' incubation after inoculation with $M$. fructicola (Table 7). The majority of the infections started from areas where fruit were touching each other and where water was retained the longest. The longer the incubation period, the higher the levels of infection in both fruit arranged in groups or incubated solitarily.

\section{DISCUSSION}

Clustering predisposes prune fruit to infection by M. fructicola. This predisposition is the result of fruit-to-fruit contact surfaces, having altered epicuticular, cuticular, and sub-epidermal characteristics, all of which contributed to higher infection levels by $M$. fructicola. Furthermore, fruitto-fruit contact surfaces created conditions that are more favorable to infections, such as retention of water for longer periods (Fig. 6), and favored germination of $M$. fructicola conidia, probably because of exuding carbohydrates.

Recovery of $M$. fructicola from surfacesterilized fruit-to-fruit contact surfaces but

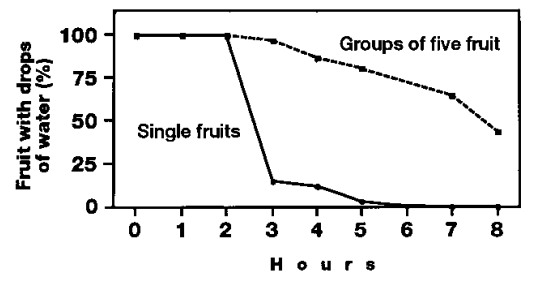

Fig. 6. Retention of water $8 \mathrm{~h}$ after spraying French mature fruit arranged in singles or groups of 5 with water to runoff at $23 \pm 1{ }^{\circ} \mathrm{C}$ and $60 \%$ relative humidity. not from non-contact surfaces suggests that infections either are better established or are more frequent in contact surfaces. Similarly to fruit-to-fruit contact surfaces, wind-scabbed areas of prune fruit surfaces, which are caused by excessive rubbing of fruit-to-fruit, fruit-to-leaf, or fruit-to-twig contact surfaces, act as traps in collecting fungal propagules and predispose fruit to fungal infection because of the presence of cracks in the fruit surface (19).

Fruit-to-fruit contact surfaces of prunes take up dyes which cannot penetrate wax, because of the presence of a thin, incomplete epicuticular wax layer in these areas (Figs. 1A and 3A). Similarly, in grapes, proper cuticle deposition is reduced and epicuticular wax formation is hindered in areas of berry-to-berry contact, with the differences in the epicuticular wax being indicated by the darker staining of the contact surfaces with methylene blue (26). Marois et al. (12) showed that bunch rot disease of grapes, caused by Botrytis cine$r e a$, starts from berry contact surfaces.

In general, increased epicuticular wax and cuticle deposition are favored by conditions of reduced relative humidity, increased light intensity, and elevated temperatures $(6,13)$. Since contact surfaces retain water longer than non-contact surfaces (Fig. 6), the relative humidity in the vicinity of the contact surfaces is expected to be higher than that of the non-contact surfaces. In contrast, the intensity of light is expected to be lower, since direct sunlight cannot penetrate among the fruit clusters. These conditions, and the rubbing and scraping between fruit due to strong winds, explain the presence of less epicuticular wax, the higher rates of conidia germination, and the better establishment of infections on fruit-to-fruit contact surfaces.

Presence of epicuticular wax imposes a barrier and a delay in the infection process by $M$. fructicola. Less epicuticular wax on fruit-to-fruit contact surfaces can cause a less flexible fruit cuticle, explaining the more frequent and longer micro-cracks (Fig. 2A) rather than the flexible cuticle of the non-contact surfaces, which are covered with dense epicuticular wax and only occasionally have small micro-cracks. Similarly, prune fruit with russet scab or wind scab have surface areas that lack epicuticular wax, resulting in less flexible cuticle that cracks more easily $(15,19)$. In nectarine fruit, development of minute cracks coincides with the time of natural brown rot infection, and the cracks have been regarded as the most likely entry sites of the pathogen (5). These cracks are of importance to infection by $M$. fructicola because they provide an unhindered access through the cuticular membrane and also allow leakage of sugary exudates, as the analyses of carbohydrate content showed, which can stimulate germination of $M$. fructicola conidia. Therefore, greater incidence of infection of clustered fruit can also be explained by a generally greater leakage of exudates, which could enhance germination of $M$. fructicola conidia. Similar findings were reported for infection of grapes by $B$. cinerea (24). Furthermore, micro-cracks detected on the surface of lychee (Litchi chinensis) pericarp increase fungal penetration into the pericarp (28).

Since infections start from contact surfaces, cultivars that have fruit produced in dense clusters can be more susceptible to brown rot than those with loose clusters. Breeding cultivars of prune for resistance to brown rot should include selecting fruit with heavy epicuticular wax and less clustering; moreover, selections that show unusually dense fruit clustering and are able to produce commercially acceptable yields should be carefully screened for their susceptibility to brown rot disease before they are named and released to growers.

Table 7. Effect of artificial fruit-to-fruit contact on infection of mature French prune by Monilinia fructicola after 7 days' incubation at $23^{\circ} \mathrm{C}$

\begin{tabular}{|c|c|c|c|c|c|}
\hline \multirow[b]{2}{*}{ Experiment } & \multirow[b]{2}{*}{ Treatment } & \multicolumn{4}{|c|}{ Incidence of infected fruit $(\%)^{\mathrm{w}}$ after day } \\
\hline & & 3 & 4 & 5 & 7 \\
\hline \multicolumn{6}{|l|}{1 (1992) } \\
\hline & Single fruit & $12.5 * \mathrm{x}$ & $41.7 *$ & $65.3 *$ & $\ldots{ }^{\mathrm{y}}$ \\
\hline & Grouped fruit ${ }^{z}$ & 68.8 & 93.7 & 97.9 & $\ldots$ \\
\hline \multicolumn{6}{|l|}{$2(1992)$} \\
\hline & $\begin{array}{l}\text { Single fruit } \\
\text { Grouned fruit }\end{array}$ & $57.1 \%$ & $\begin{array}{l}16.0^{*} \\
75.4\end{array}$ & 93.1 & $\cdots$ \\
\hline \multicolumn{6}{|l|}{$3(1993)$} \\
\hline & Single fruit & $4.1^{*}$ & $\ldots$ & $37.5^{*}$ & $61.5^{*}$ \\
\hline & Grouped fruit & 70.2 & $\ldots$ & 81.0 & 93.1 \\
\hline $4(1993)$ & Single fruit & $2.1^{*}$ & $\ldots$ & $21.4 *$ & $28.2 *$ \\
\hline & Grouped fruit & 26.3 & $\cdots$ & 49.7 & 65.8 \\
\hline
\end{tabular}

${ }^{\mathrm{w}}$ Fruit were inoculated by spraying to runoff with a suspension of $1.2 \times 10^{5} \mathrm{spores} / \mathrm{ml}$ of $M$. fructicola. Disease incidence was based on three to four replications of 24 to 36 fruit each.

$\mathrm{x} *$ indicates significant difference between single fruit and grouped fruit for each incubation time, using a pair-wise Student $t$ test $(P<0.05)$.

y Not determined.

${ }^{\mathrm{z}}$ Groups of fruit consisted of 5 or 6 fruit touching each other on at least 2 sites. 
Fruit-to-fruit contact surfaces predispose fruit to brown rot infection in three ways. First, contact surfaces apparently act as traps collecting propagules of $M$. fructicola and of other filamentous fungi and yeasts. More $M$. fructicola colonies developed from washings or from plating fruit-to-fruit contact surfaces than from those of noncontact surfaces (Table 6), suggesting better survival of the pathogen in these areas. Second, contact surfaces have thinner cuticle, allowing for an easier penetration of the pathogen. In Fantasia nectarines, fruit that developed thinner cuticle because of over-fertilization with nitrogen became more susceptible to brown rot than fruit with thicker cuticle harvested from trees not fertilized with nitrogen (17). In a similar way, cultivars of cherries (4) and plums (30) with thin cuticles were more susceptible to brown rot than those with thick cuticle. Third, infection through fruit-to-fruit contact surfaces is favored because such areas will retain rain water or dew longer, while water runs off or dries readily from the hydrophobic, waxy non-contact surfaces. Hydrophobic surfaces, such as those of the non-contact surfaces with the heavy epicuticular wax, provide extremely high water repellence (high contact angle of water droplet) in comparison with a similar surface that does not have heavy epicuticular wax (such as contact surfaces). The structure of epicuticular wax occurs in two layers in prune plums, with the incidence and complexity of the projections in the outer layer increasing as fruit matures (2). Increased sculpturing of hydrophobic surfaces decreases surface wettability (9) and adhesion of contaminating particles (i.e., fungal spores), which can be easily washed off by water droplets (anti-contamination effect; 3). Wiping the epicuticular wax with chloroform, ethyl alcohol, or even dry cotton removes or changes the orientation of wax. Such removal or changes in the orientation decreases sculpturing of plant surfaces and thus lowers hydrophobicity of the surface of waxy fruit (7).

Initiation of brown rot infections at fruitto-fruit contact surfaces, resulting in clusters of brown rot mummies, is of major importance for the epidemiology and control of brown rot of French prune. Although successful preharvest fungicide applications have been developed for other stone fruit (i.e., peach and nectarine) that are not characterized by dense clustering of fruit and on which thinning prevents the development of fruit-to-fruit contact, to date no preharvest (1 to 2 weeks) applications have been successful for prunes. A possible explanation for the unsuccessful control of mature fruit rot of French prune may be the poor fungicide coverage of dense fruit clusters, particularly the contact surfaces that become unreachable by the fungicides as the fruit enlarge. Additionally, the hydrophobic surface of prunes due to heavy epicuticular wax results in poor adhesion of fungicide droplets to the fruit surface. However, this difficulty could be bypassed either by using an extra amount of spreader-sticker additive, or using a low-volume, air-assisted application of fungicide (8). The results of this study, however, suggest that a proper timing of fungicide applications early in the season (June), before these surfaces become unreachable, would result in better coverage of contact surfaces, and two years' results on early chemical control support this hypothesis. In these studies, Michailides et al $(16,21,22)$ showed that fruit brown rot can be significantly reduced both in the field and after postharvest storage by earlysummer fungicide sprays. However, control of brown rot of prune based on the rationale of preventing infections of fruitto-fruit contact surfaces early in the season is the subject of a separate study.

Brown rot infections in clusters result in the following significant losses in comparison with solitary infected fruit: (i) one infection in a cluster will involve at least 2 fruit; (ii) clusters of mummies occupy space in harvest bins or on dryers' trays on which prunes are lined up for drying, thus resulting in increased costs for harvesting and drying by reducing efficiency of fruit drying; (iii) at grading after fruit dehydration, clusters of mummies will not go through even the largest screen and thus are mistakenly included with the large/fancy fruit. These clusters must be sorted by hand (additional costs), and their weight is added to the trash (leaves, twigs, or foreign objects) subtracted from the total weight provided by the grower and constitutes a major weight loss of dehydrated prunes. Although fruit thinning is not an established practice in prune orchards, lately mechanical thinning has been promoted, and more and more growers have started to use fruit thinning. Along with major beneficial effects on fruit size, thinning reduces fruit clustering and subsequently may reduce brown rot in prune orchards by reducing the frequency of fruit-to-fruit contact surfaces.

In conclusion, thin cuticle in fruit-tofruit contact, excessive cuticle cracking, favorable conditions for conidia germination, survival, establishment, and development of $M$. fructicola explain the high frequency of infection on contact surfaces of dense fruit clusters in the orchard. Protecting the contact surfaces by using fungicides effective against Monilinia spp., before surfaces become unreachable along with fruit thinning, should result in successful control of fruit brown rot in prune orchards in California.

\section{ACKNOWLEDGMENTS}

We thank Earl Giaccolini, Jim Bradford, Tom Jones, Jim and Jina Kells, Mike Billiou, and Doug Hughes, prune growers, for providing fruit for these experiments; L. Hou, R. Kölliker, and K. Tsuda for help in harvesting fruit and laboratory assistance; Juvenal Luza for the scanning electron and light microscopy; Guangyi Wang for carbohydrate determination; and Chuanxue Hong for reviewing this manuscript.

\section{LITERATURE CITED}

1. Adaskaveg, J. E., Feliciano, A. J., and Ogawa, J. M. 1991. Evaluation of the cuticle as a barrier to penetration by Monilinia fructicola in peach fruit. (Abstr.) Phytopathology 81:1150.

2. Bain, J. M., and McBean, D. McG. 1967. The structure of the cuticular wax of prune plums and its influence as a water barrier. Aust. J. Biol. Sci. 20:895-900.

3. Barthlott, W. 1990. Scanning electron microscopy of the epidermal surface in plants. Pages 69-83 in: Scanning Electron Microscopy in Taxonomy and Functional Morphology, Vol 41. D. Claugher, ed. Clarendon Press, Oxford.

4. Biggs, A. R., and Northover, J. 1989. Association of sweet cherry epidermal characters with resistance to Monilinia fructicola. HortScience 24:126-127.

5. Fogle, H. W., and Faust, M. 1975. Ultrastructure of nectarine surfaces. J. Amer. Soc. Hortic. Sci. 100:74-77.

6. Gay, J., and Pearce, R. 1984. The structure of plant surfaces. Pages 16-30 in: Conference Report - Infection Processes of Fungi. D. W. Roberts and J. R. Aist, eds. The Rockefeller Foundation, New York.

7. Hall, D. M. 1966. A study of the surface wax deposits on apple fruit. Aust. J. Biol. Sci. 19:1017-1025.

8. Hall, F. R. 1990. An integrated approach for improvements in application technology. Pages 453-508 in: Safer Insecticides: Development and Use. E. Hodgson and R. J. Kuhr, eds. Marcel Dekker, Inc., New York and Basel.

9. Holloway, P. J. 1970. Surface factors affecting the wetting of leaves. Pestic. Sci. 1:156-163.

10. Holloway, P. J. 1982. Structure and histochemistry of plant cuticular membranes: An overview. Pages 1-32 in: The Plant Cuticle. D. F. Cutler, K. L. Alvin, and C. E. Price, eds. Academic Press, Toronto.

11. Kennedy, J. B., and Neville, A. M. 1986 Basic Statistical Methods for Engineers and Scientists. Third edition. Harper \& Row Publishers, New York.

12. Marois, J. J., Nelson, J. K., Morrison, J. C., Lile, L. S., and Bledsoe, A. M. 1986. The influence of berry contact within grape clusters on the development of Botrytis cinerea and epicuticular wax. Am. J. Enol. Vitic. 37:293296.

13. Martin, J. T. 1964. Role of cuticle in the defense against plant diseases. Annu. Rev. Phytopathol. 2:81-100.

14. Martin, J. T., and Juniper, B. E. 1970. The Cuticles of Plants. Edward Arnold Publ., London.

15. Michailides, T. J. 1991. Russeting and russet scab of prune, an environmentally induced fruit disorder: Symptomatology, induction, and control. Plant Dis. 75:1114-1123.

16. Michailides, T. J. 1995. The "Achilles heel" of French prune. California Prune News Res. Rep. 96:1-3.

17. Michailides, T. J., Johnson, R. S., and Morgan, D. P. 1992. Effect of nitrogen fertilization on brown rot (Monilinia fructicola) susceptibility in nectarines. (Abstr.) Phytopathology 82:1064.

18. Michailides, T. J., and Morgan, D. P. 1992. Prediction of wind scab in prune orchards and predisposition of French prune fruits to postharvest fungal decay by russet scab and wind scab. Plant Prot. Q. 2(1):4-9.

19. Michailides, T. J., and Morgan, D. P. 1993 Wind scab of French prune: Symptomatology and predisposition to preharvest and postharvest fungal decay. Plant Dis. 77:90-95. 
20. Michailides, T. J., and Morgan, D. P. 1994. The influence of fruit contact on the susceptibility of French prune to Monilinia fructicola. (Abstr.) Phytopathology 84:1102.

21. Michailides, T. J., Morgan, D. P., Olson, W., Teviotdale, B., Sibbett, S., and Buchner, R. 1993. Early summer sprays control brown rot of French prune. Pages 115-139 in: Prune Res. Rep. California Prune Board, Pleasanton.

22. Michailides, T. J., Morgan, D. P., Sibbett, S. G., and Teviotdale, B. L. 1994. Management of brown rot of French prune by detecting infections in contact surfaces and by early and late summer fungicide applications. Page 24 in: Annu Res. Rep. California Prune Board, Pleasanton.
23. Michailides, T. J., Ogawa, J. M., and Opgenorth, D. C. 1987. Shift of Monilinia spp. and distribution of isolates sensitive and resistant to benomyl in California prune and apricot orchards. Plant Dis. 71:893-896.

24. Percival, D. C., Sullivan, J. A., and Fisher, K. H. 1993. Effect of cluster exposure, berry contact and cultivar on cuticular membrane formation and occurrence of bunch rot (Botrytis cinerea Pers.:Fr.) with 3 Vitis vinifera L. cultivars. Vitis 32:87-97.

25. Polito, V. S. 1981. Flower and fruit development. Pages 46-52 in: Prune Orchard Management. Div. of Agricultural Sciences. University of California, Berkeley.

26. Rosenquist, J. K., and Morrison, J. C. 1989.
Some factors affecting cuticle and wax accumulation on grape berries. Amer. J. Enol Vitic. 40:241-244.

27. Scott, T. A., and Melvin, E. H. 1953. Determination of dextran with anthrone. Anal. Chem. 25:1656-1661.

28. Underhill, S. J. R., and Simons, D. H. 1993 Lychee (Litchi chinensis Sonn.) pericarp desiccation and the importance of postharvest micro-cracking. Sci. Hortic. 54:287-294.

29. Vail, M. E., and Marois, J. J. 1991. Grape cluster architecture and the susceptibility of berries to Botrytis cinerea. Phytopathology 81:188-191.

30. Valleau, W. D. 1915. Varietal resistance to brown-rot. J. Agric. Res. 5(9):365-396. 